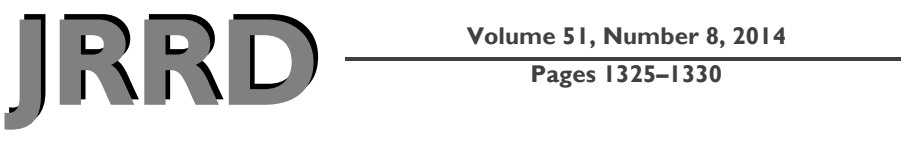

\title{
Cost of lower-limb amputation in U.S. veterans with diabetes using health services data in fiscal years 2004 and 2010
}

\author{
Heather Franklin, MPH; ${ }^{1-2}$ Mangala Rajan, MBA; ${ }^{1-3}$ Chin-Lin Tseng, DrPH; ${ }^{1,3}$ Len Pogach, MD, MBA; ${ }^{1,3}$ \\ Anushua Sinha, MD, MPH ${ }^{1-3^{*}}$ \\ ${ }^{1}$ Department of Veterans Affairs New Jersey Health Care System, East Orange Campus, East Orange, NJ; ${ }^{2}$ Department of \\ Quantitative Methods, Rutgers School of Public Health, Newark, NJ; ${ }^{3}$ Department of Preventive Medicine and Commu- \\ nity Health, New Jersey Medical School, Rutgers-The State University of New Jersey, Newark, NJ
}

\begin{abstract}
The purpose of this study was to estimate healthcare costs associated with diabetes-related lower-limb amputations (LLAs) within the Veterans Health Administration (VHA). We performed a cross-sectional comparative analysis of 3,381 VHA clinic users in fiscal year (FY) 2004 and 3,403 VHA clinic users in FY2010 identified as having type 2 diabetes mellitus and nontraumatic LLA. LLA expenditures related to inpatient medical, inpatient surgical, and outpatient care were estimated using VHA Health Economics Resource Center average cost files. LLA-related pharmaceutical costs were obtained from VHA Decision Support Systems national extract files. From the Department of Veterans Affairs (VA) perspective, the mean cost associated with care for diabetes-related LLA per patient in the VA healthcare system in FY2004 was $\$ 50,351$ (95\% confidence interval $[\mathrm{CI}]=48,939-51,803$ ) in 2012 U.S. dollars; the total cost for all 3,381 patients was $\$ 170,236,037$. In FY2010, cost per patient rose to $\$ 60,647$ $(95 \%$ CI $=59,143-62,188)$, with a total cost of $\$ 206,380,331$ for 3,403 patients. In the VHA healthcare system, the economic burden associated with LLAs in patients with diabetes exceeded \$200,000,000 in FY2010. This suggests that further improvements in care of patients with diabetes could be associated with significant cost savings.
\end{abstract}

Key words: amputations, cost, diabetes, health services, LLA expenditures, lower-limb amputations, VA, veteran, Veterans Health Administration, VHA.

\section{INTRODUCTION}

Diabetes mellitus type 2 currently affects roughly one in four U.S. veterans, resulting in a 10 - to 20 -fold increased risk of lower-limb amputation (LLA) among those with diabetes [1]. LLAs are burdensome, both in terms of the patient's quality of life and in healthcare costs. The direct medical costs for diabetic patients with LLA in the United States in 2001 totaled \$1.65 billion, nearly 2 percent of all diabetes-related healthcare costs [2]. The functional disability associated with LLA includes problems with mobility, self-care, and social and emotional isolation [3], and diabetic patients with LLA have an increased risk of comorbid disease and death from cardiovascular disease. LLAs serve as a marker of poor glycemic control and, as a result, LLAs are assessed as a

\footnotetext{
Abbreviations: $\mathrm{CI}=$ confidence interval, DSS = Decision Support Systems, FY = fiscal year, HERC $=$ Health Economics Resource Center, ICD-9 = International Classification of Diseases-Ninth Revision, IQR = interquartile range, LLA = lowerlimb amputation, VA = Department of Veterans Affairs, VHA = Veterans Health Administration.

*Address all correspondence to Anushua Sinha, MD, MPH; Rutgers New Jersey Medical School, Medical Science Building-Rm F506, 185 South Orange Ave, Newark, NJ 07101-1709; fax: 973-972-7625.

Email: sinhaan1@njms.rutgers.edu

http://dx.doi.org/10.1682/JRRD.2013.11.0249
} 
prevention quality indicator by the Agency for Healthcare Research and Quality and are reflective of the quality of foot care delivered within a healthcare system [4-5].

The Veterans Health Administration (VHA) is the largest provider of managed care health services in the United States. It has had electronic medical health records for individual patients for the last two decades. Prior VHA studies have estimated the prevalence of any LLA at 8 per 1,000 among veterans with type- 2 diabetes and initial amputation rates at 6 per 1,000 [6]. Subsequent studies have found that initial LLA rates have been decreasing in the veteran population with diabetes for both minor and major amputations [7]. However, no study has estimated VHA costs associated with LLA in patients with diabetes. Therefore, the aim of this study was to estimate and compare the individual-level healthcare costs associated with LLA within the VHA in fiscal year (FY) 2004 and FY2010, focusing on those costs associated with the surgical procedure itself.

\section{METHODS}

This was a cross-sectional analysis of VHA clinic users with diabetes in FY2004 and FY2010. Using previously validated and described methods [8], we identified diabetic VHA users by the presence of two different outpatient or inpatient episodes associated with diabetesrelated International Classification of Diseases-Ninth Revision (ICD-9) diagnosis codes during the year of interest or the prior year (24 mo period) or the prescription of medications for glycemic control in the year of interest. Data from the Department of Veterans Affairs (VA) inpatient Patient Treatment File and Outpatient Event files were used in this determination. Cost data for inpatient and outpatient utilization were acquired from the VA Health Economics Resource Center (HERC) [9-10]. Medication costs were calculated from prescription data in the Decision Support Systems (DSS) pharmacy files. Preliminary analysis demonstrated that costs are rightskewed and do not conform to a normal distribution. Therefore, individual patient's costs are presented with two measures: means and medians ( \pm 1 st quartile, 3rd quartile); sums are reported to demonstrate total burden. Estimates of mean costs were separately derived for FY2004 and FY2010. We estimated the mean total cost and its 95 percent confidence interval (CI), as well as mean cost by amputation level, using an "empty" model (no independent variables) based on a gamma distribution to account for the skewed distribution of the cost data.

Amputation procedures done in a VHA hospital were identified based on the presence of an associated ICD-9 procedure code (toe amputation [84.11], transmetatarsal and below-knee amputation [84.12-84.16], above-knee amputation [84.17-84.19]) [8]. Each patient was categorized according to his or her highest anatomic level amputation because studies have shown that significant numbers of lower levels of amputations may progress to subsequent, higher-level amputations [11-12].

Costs were estimated from the VHA perspective. For costs related to VHA inpatient and outpatient services in FY2004 and FY2010, cost estimates from HERC average cost files were used [7]. HERC's average costing approach assumes that each healthcare encounter has the average cost of all encounters with the same characteristics. HERC estimates for acute medical-surgical inpatient stays are based on a cost regression method that uses Medicare data as a comparable non-VHA data set to model the relationship between cost and the characteristics of the stay. It then combines the model with VHA data to estimate predicted cost and then adjusts the result to reflect total annual VHA expenditures [10].

All outpatient costs $30 \mathrm{~d}$ prior to and $60 \mathrm{~d}$ post-LLA were considered surgery-related and were included in the analysis. Costs for surgery-related medications were obtained from VHA DSS national extract data and included all inpatient and discharge medications dispensed within $7 \mathrm{~d}$ of inpatient discharge following amputation. All costs have been Consumer Price Index inflation-adjusted to 2012 U.S. dollars [13]. Analyses were conducted using SAS software version 9.2 (SAS Institute Inc; Cary, North Carolina).

\section{RESULTS}

We identified 1,003,052 and 1,260,018 veterans with diabetes in FY2004 and FY2010, respectively. The majority were male (99\%), white (FY2004: 61\%; FY2010: 64\%), and with a mean age of 66 yr (FY2004) and 63 yr (FY2010). Relative to FY2004, in FY2010 patients receiving LLA rose from 3,381 to 3,403, but fewer received more than one LLA (12.2\% in FY2004 vs $11.3 \%$ in FY2010). Toe amputation was the most common LLA, affecting 1,373 veterans (41\%) in FY2004 and 1,454 (41\%) in FY2010. Proportions of patients with diabetes undergoing amputation within the VHA system 
decreased from 337/100,000 (95\% CI: 326-348/100,000) in FY2004 to 270/100,000 (95\% CI: 261-279/100,000) in FY2010.

The overall median length of stay was $13 \mathrm{~d}$ in FY2004 and $11 \mathrm{~d}$ in FY2010. This decrease is apparent across all amputation levels: toe (FY2004: 10, interquartile range [IQR] 6, 18; FY2010: 8, IQR 5, 14), below knee (FY2004: 15, IQR 8, 25; FY2010: 12, IQR 7, 21), and above knee (FY2004: 16, IQR 9, 29; FY2010: 15, IQR 9, 25).

Overall, the mean cost of care for individual patients with LLA increased from \$50,351 (95\% CI: \$48,939$\$ 51,803$ ) in FY2004 to $\$ 60,647$ (95\% CI: $\$ 59,143-$ $\$ 62,188$ ) in FY2010, and the median increased from \$33,927 (IQR: \$18,742, \$62,796) in FY2004 to \$43,528 (IQR: \$25,429, \$74,607) in FY2010. In FY2004, inpatient surgery accounted for 89.8 percent of LLA-associated direct medical costs, followed by pharmacy $(7.0 \%)$ and outpatient visits (3.2\%). In FY2010, these proportions for LLA-associated direct medical costs were inpatient surgery (88.3\%), outpatient visits (6.2\%), and pharmacy (5.5\%). By level of amputation, the mean total direct medical costs for individual patients were least for toe amputations (FY2004: \$33,205, 95\% CI: \$31,845-\$34,622); FY2010: \$41,484, 95\% CI: \$40,075-42,943) and greatest for the most extensive procedure, above-knee amputations (FY2004: \$69,726, 95\% CI: \$65,275-\$74,481; FY2010: \$82,758, 95\% CI: \$78,063-\$87,736) (Table).

The amputation-related costs incurred by the VHA in FY2004 totaled \$170,236,037, 0.66 percent of VHA total annual expenditures, and \$206,380,331 in FY2010, 0.51 percent of VHA total annual expenditures. The proportion of VHA annual inpatient expenditure attributed to amputation-related costs decreased from 1.76 percent in FY2004 to 1.25 percent in FY2010, whereas the proportion of VHA annual outpatient expenditures attributed to amputation-related costs increased from 0.05 percent in FY2004 to 0.07 percent in FY2010. The proportion of VHA annual pharmacy expenditures attributed to amputation-related costs remained constant at 0.2 percent.

\section{DISCUSSION}

Among veterans with diabetes, the individual mean cost associated with an LLA in the VHA system in FY2004 was $\$ 50,351$; in total, the economic burden associated with LLA in this population was more than $\$ 170$ million. In FY2010, the mean cost was $\$ 60,647$ with an economic burden of more than \$206 million. Patients with higher anatomic levels and/or multiple amputations had markedly increased costs for inpatient surgery and pharmacy but lower outpatient costs, possibly because in the VHA system, a longer period of recovery and rehabilitation occurs in the inpatient setting for these patients. Of note, this analysis was done from the VHA perspective and did not include costs incurred outside VHA.

Consistent with previous reports [7], we observed a decreased proportion of VHA users with diabetes undergoing LLA. However, because of the increasing numbers of veterans with diabetes, the number of LLAs increased slightly in 2010 relative to 2004. Fewer VHA patients underwent multiple amputations and length of stay per amputation decreased, but the apparent economic burden of LLA continued to rise. This was not only because of the increase in the number of LLAs but also because of an apparent increase in the cost per LLA. The latter increase may be explained in part by changes to the diagnosis-related groups used by Medicare [12] to determine reimbursement rates, as well as the HERC costing approach that employs both a FY adjustment and a national scaling factor to fit Medicare data to the VHA annual budget.

Previous studies have also found a large economic burden associated with diabetes-related LLA. In 2003, Brandle et al. estimated the $1 \mathrm{yr}$ median cost of an amputation event as $\$ 37,600(\$ 23,300-\$ 62,200)$ in 2003 dollars [13]. In a 2008 study, the mean total annual Medicare payments for any beneficiary with a diabetes-related LLA was estimated at approximately $\$ 52,000$, reported in 2008 dollars [14]. Neither study is directly comparable to this study, which focused on the VHA economic perspective and on the amputation event rather than the total annual medical costs of patients who had an amputation in that year.

This study was limited in that rehabilitation and prosthetic costs were captured only if they were provided during hospitalization. While an episode of care approach has been used in the literature, costing an episode of care requires access to data encompassing care both within and outside the VHA system. The purpose of this study was to develop costs of care from the VHA perspective only, so costs outside the VHA system were not included. Previous studies have found higher rates of progression from toe amputations to higher levels [15-16] relative to our findings. This difference may be explained by our choice to limit our analysis to amputations occurring within a fiscal year. Additionally, amputations that 
JRRD, Volume 51, Number 8, 2014

Table.

Mean and median direct medical costs associated with diabetes-related lower-limb amputations, Veterans Health Administration. All costs are expressed in 2012 U.S. dollars (USD 2012).

\begin{tabular}{|c|c|c|c|c|c|c|}
\hline $\begin{array}{l}\text { Amputation Level } \\
\text { (\% of total) }\end{array}$ & $\begin{array}{c}\text { Cost } \\
\text { Category }\end{array}$ & $N$ & $\begin{array}{c}\text { \% Missing } \\
\text { Data }\end{array}$ & $\begin{array}{l}\text { Mean,* USD } 2012 \\
\text { (95\% CI) }\end{array}$ & $\begin{array}{c}\text { Median, USD } 2012 \\
\text { (IQR) }\end{array}$ & Sum, USD 2012 \\
\hline \multicolumn{7}{|l|}{ FY2010 } \\
\hline \multirow[t]{3}{*}{ All Levels } & Total & 3,403 & - & $60,647(59,143-62,188)$ & $43,528(25,429-74,607)$ & $206,380,331$ \\
\hline & Outpatient & & 6.80 & $4,043(3,907-4,184)$ & $2,506(1,316-4,556)$ & $12,825,608$ \\
\hline & Pharmacy & & 0.01 & $3,324(3,217-3,335)$ & $1,911(1,058-3,704)$ & $11,308,562$ \\
\hline & Outpatient & & 2.20 & 4,441 (4,229-4,664) & 2,857 (1,553-4,918) & $6,311,032$ \\
\hline & Pharmacy & & 0.00 & $2,775(2,643-2,913)$ & 1,633 (973-3,126) & $4,034,303$ \\
\hline \multirow[t]{3}{*}{ Below Knee (38.3\%) } & Total & 1,303 & - & $71,067(68,449-73,785)$ & $55,019(34,230-89,063)$ & $92,600,714$ \\
\hline & Inpatient & & 0.00 & $63,918(61,423-66,513)$ & 48,885 (28,589-80,299) & $83,284,553$ \\
\hline & Outpatient & & 8.70 & 3,862 (3,653-4,082) & 2,464 (1,281-4,379) & $4,595,341$ \\
\hline & Outpatient & & 13.20 & 3,421 (3,129-3,741) & 1,829 (961-3,667) & $1,919,235$ \\
\hline & Pharmacy & & 0.00 & $3,953(3,642-4,290)$ & $2,143(1,073-4,098)$ & $2,553,439$ \\
\hline \multicolumn{7}{|l|}{ FY2004 } \\
\hline \multirow[t]{4}{*}{ All Levels } & Total & 3,381 & - & $50,351(48,939-51,803)$ & 33,927 (18,742-62,796) & $170,236,037$ \\
\hline & Inpatient & & 0.00 & $45,236(43,886-46,626)$ & $29,822(15,564-56,675)$ & $152,941,577$ \\
\hline & Outpatient & & 8.80 & $1,766(1,708-1,827)$ & $1,257(581-2,280)$ & $5,449,187$ \\
\hline & Pharmacy & & 0.40 & 3,517 (3,389-3,650) & 1,661 (816-3,628) & $11,845,273$ \\
\hline \multirow[t]{3}{*}{ Toe $(40.6 \%)$} & Total & 1,373 & & $33,205(31,845-34,622)$ & $22,981(14,224-40,848)$ & $45,589,911$ \\
\hline & Inpatient & & 0.00 & $28,882(27,584-30,241)$ & $19,325(10,970-36,006)$ & $39,655,505$ \\
\hline & Outpatient & & 2.50 & $1,784(1,702-1,870)$ & 1,338 (707-2,318) & 2,386,906 \\
\hline & Outpatient & & 15.60 & $1,549(1,421-1,687)$ & $1,027(402-2,001)$ & 844,014 \\
\hline & Pharmacy & & 0.00 & $5,347(4,863-5,880)$ & $2,034(970-4,338)$ & $3,454,332$ \\
\hline
\end{tabular}

${ }^{*}$ Geometric mean.

$\mathrm{CI}=$ confidence interval, $\mathrm{FY}=$ fiscal year, $\mathrm{IQR}=$ interquartile range.

occurred outside the VHA system, such as through Medicare-covered services, were not included since our focus was on estimating costs within the VHA system.

\section{CONCLUSIONS}

This study costs multiple episodes incurred within a fiscal year and attributes them to the highest level of amputation performed. VHA has seen significant improvements in diabetes care [17]. For example, evaluation in the VHA of veterans with diabetes has demonstrated a 5 yr (2000-2004) significant downward trend of all types of amputations [7]. However, this study demonstrates that further improvements in diabetes care delivery will be needed to control the costs of diabetesassociated complications such as LLA as the numbers of veterans with diabetes grows. 


\section{ACKNOWLEDGMENTS}

Author Contributions:

Study concept: H. Franklin, M. Rajan, A. Sinha.

Study design: H. Franklin, M. Rajan, C. Tseng, A. Sinha.

Acquisition of data: M. Rajan, C. Tseng, L. Pogach.

Analysis and interpretation of data: H. Franklin, M. Rajan, C. Tseng, A. Sinha.

Drafting of manuscript: H. Franklin, M. Rajan, C. Tseng, L. Pogach, A. Sinha.

Financial Disclosures: The authors have declared that no competing interests exist.

Funding/Support: This material was based on work supported by the VA Health Services Research \& Development Service (pilot grant 10289).

Additional Contributions: The authors thank Jean Yoon for helpful comments.

Institutional Review: This study was approved by the VA New Jersey Health Care System Institutional Review Board.

\section{REFERENCES}

1. Wrobel JS, Mayfield JA, Reiber GE. Geographic variation of lower-extremity major amputation in individuals with and without diabetes in the Medicare population. Diabetes Care. 2001;24(5):860-64. [PMID:11347744] http://dx.doi.org/10.2337/diacare.24.5.860

2. Gordois A, Scuffham P, Shearer A, Oglesby A, Tobian JA. The health care costs of diabetic peripheral neuropathy in the US. Diabetes Care. 2003;26(6):1790-95.

[PMID:12766111] http://dx.doi.org/10.2337/diacare.26.6.1790

3. Peters EJ, Childs MR, Wunderlich RP, Harkless LB, Armstrong DG, Lavery LA. Functional status of persons with diabetes-related lower-extremity amputations. Diabetes Care. 2001;24(10):1799-1804. [PMID:11574445] http://dx.doi.org/10.2337/diacare.24.10.1799

4. AHRQ Quality Indicators prevention quality indicators overview. Rockville (MD): Agency for Healthcare Research and Quality; 2004.

5. Office of Disease Prevention and Health Promotion. Diabetes. In: Healthy people 2010. Washington (DC): Department of Health and Human Services; 2010 [cited 2013 Nov 11]. Available from: http://www.healthypeople.gov/2010/ document/pdf/volume1/05diabetes.pdf?visit=1

6. Sambamoorthi U, Tseng CL, Rajan M, Anjali T, Findley PA, Pogach L. Initial nontraumatic lower-extremity amputations among veterans with diabetes. Med Care. 2006; 44(8):779-87. [PMID:16862041] http://dx.doi.org/10.1097/01.mlr.0000218793.74558.0e

7. Tseng CL, Rajan M, Miller DR, Lafrance JP, Pogach L. Trends in initial lower extremity amputation rates among
Veterans Health Administration health care system users from 2000 to 2004. Diabetes Care. 2011;34(5):1157-63.

[PMID:21411510]

http://dx.doi.org/10.2337/dc10-1775

8. Miller DR, Safford MM, Pogach LM. Who has diabetes? Best estimates of diabetes prevalence in the Department of Veterans Affairs based on computerized patient data. Diabetes Care. 2004;27(Suppl 2):B10-21. [PMID:15113777] http://dx.doi.org/10.2337/diacare.27.suppl_2.B10

9. Barnett PG. Determination of VA health care costs. Med Care Res Rev. 2003;60(3 Suppl):124S-41S.

[PMID:15095549] http://dx.doi.org/10.1177/1077558703256483

10. Wagner TH, Chen A, Yu W, Barnett PG. HERC's average cost datasets for VA inpatient care FY1998-FY2008. Washington (DC): Veterans Health Administration; 2008.

11. Bureau of Labor Statistics. Consumer price index. Washington (DC): Department of Labor; 2012.

12. Centers for Medicare \& Medicaid Services. Acute inpatient PPS [Internet]. Washington (DC): Centers for Medicare \& Medicaid Services; 2013 [cited 2013 Nov 11]. Available from: http://www.cms.gov/Medicare/Medicare-Fee-forService-Payment/AcuteInpatientPPS/index.html

13. Brandle M, Zhou H, Smith BR, Marriott D, Burke R, Tabaei BP, Brown MB, Herman WH. The direct medical cost of type 2 diabetes. Diabetes Care. 2003;26(8):2300-4.

[PMID:12882852] http://dx.doi.org/10.2337/diacare.26.8.2300

14. Margolis DJ, Malay DS, Hoffstad OJ, Leonard CE, MaCurdy T, Tan Y, Molina T, de Nava KL, Siegel KL. Economic burden of diabetic foot ulcers and amputations. Washington (DC): Agency for Healthcare Research and Quality; 2011.

15. Griffin KJ, Rashid TS, Bailey MA, Bird SA, Bridge K, Scott JD. Toe amputation: A predictor of future limb loss? J Diabetes Complications. 2012;26(3):251-54.

[PMID:22516530]

http://dx.doi.org/10.1016/j.jdiacomp.2012.03.003

16. Stone PA, Back MR, Armstrong PA, Flaherty SK, Keeling WB, Johnson BL, Shames ML, Bandyk DF. Midfoot amputations expand limb salvage rates for diabetic foot infections. Ann Vasc Surg 2005;19(6):805-11.

[PMID:16205848]

http://dx.doi.org/10.1007/s10016-005-7973-3

17. Kerr E. Assessing quality health care for diabetes. Rockville (MD): Agency for Healthcare Research and Quality; 2006.

Submitted for publication November 22, 2013. Accepted in revised form July 3, 2014. 
JRRD, Volume 51, Number 8, 2014

This article and any supplementary material should be cited as follows:

Franklin H, Rajan M, Tseng C, Pogach L, Sinha A. Cost of lower-limb amputation in U.S. veterans with diabetes using health services data in fiscal years 2004 and 2010. J
Rehabil Res Dev. 2014;51(8):1325-30.

http://dx.doi.org/10.1682/JRRD.2013.11.0249

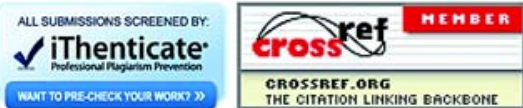

